\title{
TRAS LOS PASOS DE LA EVIDENCIA CIENTÍFICA: LA RAZONABILIDAD EN EL EJERCICIO DEL PODER DE POLICÍA SANITARIO FRENTE A LA INCERTIDUMBRE CLÍNICA ${ }^{1}$
}

Scientific evidence: the reasonableness in the exercise of the Health Police Power in the face of clinical uncertainty

Prove scientifiche: la ragionevolezza nell'esercizio del Potere di Polizia della Sanità di fronte all'incertezza clínica

Federico G. Menéndez ${ }^{2}$

Recibido: 15 de mayo de 2020

Aprobado: 15 de junio de 2020

Resumen: El principio rector de la evaluación de eficacia y seguridad de las prestaciones médicas es la incertidumbre clínica o también llamado "equipoise". En un escenario global gobernado por la ausencia de consenso racional sobre los efectos de determinados tratamientos para combatir el virus identificado como SARS-CoV, el Estado tiene un rol determinante como garante del Bien Común a través del ejercicio del Poder de Policía sanitario. En los casos de discusiones científicas la jurisprudencia, la Deontología Médica y el Derecho proponen como criterio de razonabilidad el trinomio compuesto por la efectividad objetiva del tratamiento a la luz de la evidencia

1 El autor agradece los comentarios del médico neumonólogo Alejandro Videla.

2 Centro de Investigación y Estudios Superiores del Instituto de Cultura del Centro Universitario de Estudios CUDES, Buenos Aires, Argentina. Abogado por la Universidad Nacional de la Matanza y Magíster en Derecho Administrativo por la Universidad Austral. Es Director del Instituto de Investigación y Estudios Superiores del Instituto de Cultura del Centro Universitario de Estudios CUDES y profesional independiente. Correo electrónico: fed.menendez@gmail.com. 
científica, la opinión profesional libre e independiente y el respeto al ámbito de discrecionalidad médica.

Palabras clave: Poder de Policía sanitario; Derecho a la salud; COVID-19; Razonabilidad.

\begin{abstract}
The guiding principle for evaluating the efficacy and safety of medical benefits is clinical uncertainty or also called "equipoise". In a global scenario governed by the absence of rational consensus on the effects of certain treatments to combat the virus identified as SARS-CoV, the State has a determining role as guarantor of the Common Good through the exercise of the Power of the Sanitary Police. In cases of scientific discussions, jurisprudence, Medical Deontology and Law propose as a criterion of reasonableness the trinomial composed of the objective effectiveness of the treatment in light of scientific evidence, free and independent professional opinion and respect for the field of medical discretion.
\end{abstract}

Keywords: Power of Sanitary Police; Right to Health; COVID-19; Reasonableness.

Sommario: Il principio guida per la valutazione dell'efficacia e della sicurezza dei benefici medici è l'incertezza clinica o anche chiamata "equipoise". In uno scenario globale governato dall'assenza di un consenso razionale sugli effetti di alcune terapie per combattere il virus identificato come SARS$\mathrm{CoV}$, lo Stato ha un ruolo determinante come garante del bene comune attraverso l'esercizio del potere di polizia della sanità. In caso di discussioni scientifiche, giurisprudenza, deontologia medica e legge, propongono come criterio di ragionevolezza il trinomio costituito dall'efficacia oggettiva della terapia alla luce di prove scientifiche, l'opinione professionale libera e indipendente e il rispetto nell'ambito della discrezionalità medica.

Parole chiave: Potenza della Polizia della Sanità; Diritto alla salute; COVID-19; Ragionevolezza

Para citar este artículo: Menéndez, F.G. (2020). “Tras los pasos de la evidencia científica: la razonabilidad en el ejercicio del Poder de Policía sanitario frente a la incertidumbre clínica". Prudentia Iuris, N. 90, pp. 59-78 DOI: https://doi.org/10.46553/prudentia.90.2020.pp.59-78 


\section{Introducción}

Desde hace ya varias semanas, todo el orbe se encuentra expectante al desarrollo del virus identificado como SARS-CoV. En nuestro país, quedan lejanas e inocentes las medidas preventivas recomendadas por el Ministerio de Educación a través de su Resolución $N^{\circ}$ 82/2020. El itinerario jurídico que ha tocado transitar muestra una primera cuasi ingenuidad (nos atrevemos a decir) que luego fue, veloz y exponencialmente, generando una profusa producción normativa, encontrando su clímax en el Decreto $\mathrm{N}^{\circ}$ 260/2020 del Poder Ejecutivo Nacional, por el cual se ampliaba la Emergencia Pública en materia sanitaria hasta el 12 de marzo de 2021.

La declaración de pandemia por la Organización Mundial de la Salud el 11 de marzo de este año ha motivado la investigación científica en búsqueda de una salida posible a la emergencia. En estos días, muchos papers han salido a la luz procurando brindar respuesta a las demandas de las instituciones de salud, con vocación de paliar los cuadros críticos y disminuir la cantidad de infectados por el virus.

Sin desconocer la seriedad con la cual desarrollan sus investigaciones y el ahínco por la búsqueda de una solución a la crisis, es un dato objetivo la existencia de una multiplicidad de estudios de las fuentes más diversas y con propuestas de lo más disímiles. Tan sólo a modo de ejemplo, podemos mencionar los estudios acerca del valor protector del receptor de acetilcolina nicotínico ${ }^{3}$, o los estudios de eficacia de la hidroxicloroquina ${ }^{4}$, o los propios de Lopinavir-Ritonavir ${ }^{5}$.

El principio rector de la evaluación de eficacia y seguridad de los medicamentos es la incertidumbre clínica (equipoise) que establece que en ausencia de pruebas contundentes de la capacidad de curar y de la ausencia de efectos adversos no aceptables, los médicos no deben recomendar tratamientos. Los tratamientos experimentales solo se pueden administrar en el contexto de ensayos clínicos aleatorizados y controlados con placebo a personas que hayan dado su consentimiento informado con plena libertad ${ }^{6}$.

3 Cfr. Changeux, J., et al. (Abril 2020). "A nicotinic hypothesis for COVID-19 with preventive and therapeutic implications". Qeios, https://doi.org/10.32388/FXGQSB.2.

4 Cfr. Chen, J., et al. (Marzo 2020). "A pilot study of hydroxychloroquine in treatment of patients with common coronavirus disease-19 (COVID-19)". Journal of Zhejiang University, Nro. 46, 215-219.

5 Cfr. Cao, Y., et al. (Marzo 2020). "A Trial of Lopinavir-Ritonavir in Adults Hospitalized with Severe COVID-19". The New England Journal of Medicine, Nro. 382, 1787-1799.

6 Cfr. Freedman, B. (Julio 1987). "Equipoise and the Ethics of Clinical Research". The New England Journal of Medicine, Nro. 317, 141-145. 
La preocupación creada por la carga de morbilidad y mortalidad que acarrea la pandemia ha puesto en riesgo este principio. La presencia de plausibilidad biológica, la existencia de incentivos financieros, las presiones de los pacientes y la misma buena voluntad de ayudar y de curar de los proveedores de salud han conducido, según algunos galenos, a esta situación ${ }^{7}$.

En esta línea, el Estado, como garante del Bien Común, debe intervenir (siempre que las circunstancias lo requieran) en defensa de la sociedad y el cuidado de la higiene, procurando la conservación de la salud pública para dar cumplimiento a uno de sus fines permanentes: el mantenimiento del derecho a la salud. En palabras de Soler: "[l]a acción que el Estado ha de ejercer para la mejor conservación de la salud pública constituye el objeto de esta policía; acción que no es solo negativa, evitando los ataques a la salud, sino también positiva, poniendo los medios conducentes a su restablecimiento cuando ha sido alterada"8.

En este estado de situación, frente a la multiplicidad de "oferta académica" relacionada con el tema y diversidad de posiciones sobre el diagnóstico y pronóstico del escenario global, muchos profesionales de la salud se han mostrado críticos a estudios que proponen tratamientos o fármacos con supuesto carácter antiviral. Algunos han manifestado que incluso contando con tratamientos que se mostraren idóneos para el combate de la enfermedad, debería pasar tiempo hasta darle un estatus de probatus. Así las cosas, en un contexto de genuina y honesta preocupación por una salida de la emergencia sanitaria frente a un panorama de incertidumbre clínica, nos preguntamos: ¿cuál sería una postura razonable a asumir por el Estado en su rol de contralor sanitario?

En este punto, entendemos que la clave de bóveda estará dada por el interés superior del paciente que orientará una respuesta aceptable desde el punto de vista jurídico y médico. Para ello será necesario revisar el carácter de la verdad científica y la razonabilidad del ejercicio del Poder de Policía en este contexto, partiendo de la incertidumbre clínica.

\section{La Medicina, materia objeto de análisis}

La Filosofía de la Ciencia ubica a la Medicina dentro de las Ciencias Experimentales. En este ámbito, diversos autores han analizado las carac-

7 Cfr. Kramer, D., et al. (7 de abril 2020). "Equipoise on COVID-19 therapeutics". The BMJ Opinion, https://www.blogs.bmj.com/bmj/2020/04/07/equipoise-on-life-support.

8 Soler Pérez, E. (2015). Derecho Administrativo: Lecciones de la Universidad de Valencia 1906-1907. Sevilla. Athenaica Ediciones Universitarias, 295. 
terísticas y el criterio de validez de la verdad científica, y se han generado posiciones antagónicas, algunas moderadas y otras más radicales.

Partiendo de la percepción social actual, la verdad científica goza de prestigio y se acepta como conocimiento fiable ${ }^{9}$. Algunos filósofos de la ciencia atribuyen esa fiabilidad, entre otros motivos, al valor demostrable ${ }^{10}$ de las proposiciones científicas y al carácter controlable gracias a su repetitividad experimental ${ }^{11}$. Asimismo, es un hecho que la verdad científica es fruto de la cooperación intelectual orientada a conseguir el mayor consenso racional posible sobre ella ${ }^{12}$.

No obstante, existen parcelas del conocimiento científico que se encuentran in fieri o donde aún no hay acuerdo sobre el valor de las afirmaciones, en gran medida por el carácter progresivo del conocimiento científico. Podemos decir que el conocimiento tiene una cadencia, un tiempo propio que permite la maduración de sus proposiciones. El Derecho recoge este aprendizaje en diversas normas, resaltando los períodos de prueba y experimentación, previos a que la ciudadanía tenga acceso al adelanto científico ${ }^{13}$.

Ello acarrea que este optimismo sobre el criterio de verdad científica conozca matices desde lo epistemológico. Diversos autores han reconocido que aquella tiene un carácter limitado ${ }^{14}$, provisorio ${ }^{15}$, condicionada por el obrar humano ${ }^{16}$, contextual ${ }^{17}$, construida a partir de conceptos a priori convencionales ${ }^{18}$, parcial ${ }^{19}$ y cuyo conocimiento admite diversos grados de certeza ${ }^{20}$.

Como ciencia experimental, la Medicina es una disciplina que emplea métodos empíricos. La aproximación a la verdad solo se obtiene por la realización y repetición de experimentos controlados, ya que la biología conlleva una gran variabilidad de respuestas individuales. Se acepta universalmente que el mayor estándar técnico lo representan los estudios clínicos

9 Cfr. Artigas, M. (1999). Filosofía de la Ciencia. Navarra. Ediciones Universidad de Navarra S.A. (EUNSA), 255.

10 Ibíd., 22.

11 Ibíd., 135.

12 Cfr. Ziman, J. (1981). La credibilidad de la ciencia. Madrid. Alianza, 224.

13 En este punto podemos destacar lo mencionado por el artículo 11 de la Ley $\mathrm{N}^{\circ} 16.463$, que procura, a través de revisiones periódicas, la adecuación del fármaco autorizado al progreso de la ciencia.

14 Cfr. De Broglie, L. (1955). Physiscs and Microphysics. Traducción de Davidson, M. Nueva York. Panteon Books, 84.

15 Cfr. Artigas, M. (1999). Filosofía... Ob. cit., 161.

16 Ibíd., 167.

17 Ibíd., 169.

18 Cfr. Hubner, K. (1981). Crítica de la razón científica. Barcelona. Alfa, 115.

19 Cfr. Artigas, M. (1999). Filosofía... Ob. cit., 233.

20 Ibíd., 244. 
controlados contra placebo y controlados aleatorizados y las revisiones de múltiples estudios de este tipo ${ }^{21}$.

En definitiva, definir el criterio de verdad científica no resulta una tarea sencilla. Ello trae consigo una verdadera dificultad para el Derecho que se encuentra en diálogo constante con la Ciencia Médica y requiere de criterios concretos para su valoración en el caso particular. Algunos tribunales foráneos tuvieron ocasión de expedirse al respecto buscando aportar luces para que los jueces analicen y ponderen el alcance de la evidencia científica en casos complejos ${ }^{22}$.

Desde esta otra rama del saber, la CSJN, a lo largo de su jurisprudencia de los últimos cuarenta años, ha llegado a una conclusión compatible con la filosófica. Para el Máximo Tribunal, la verdad científico-médica es limitada $^{23}$, provisoria ${ }^{24}$, falible ${ }^{25}$, progresiva ${ }^{26}$, en buena medida opinable ${ }^{27}$, dinámica ${ }^{28}$ y muchas veces su conocimiento resulta dificultoso debido a la concausalidad y concatenación de los elementos que la componen ${ }^{29}$. De igual manera que sucede en el debate académico médico, en todos los casos donde no se plantean discusiones de índole técnica, la CSJN asume pacíficamente la verdad traída por las partes. En cambio, en los casos de controversias, la

21 Cfr. University Of Camberra (2019). "Evidence-Based Practice in Health", 16-6-2020, University Of Caberra Library. Recuperado de: canberra.libguides.com/c. php?g=599346\&p=4149721.

22 Por ejemplo, en el histórico Fallo "Daubert v. Merrell Dow Pharmaceuticals", Inc., 509 U.S. 579 (1993), la Suprema Corte Federal de Estados Unidos estableció las previsiones que han de tenerse para aceptar el dictamen técnico altamente especializado. A saber: 1) Que respecto del conocimiento de que se trata, exista un consenso general por parte de la comunidad científica; es decir, se excluye su utilización cuando medien dudas acerca de su validez epistemológica. 2) Que de alguna manera sea empíricamente verificable. 3) Que, en su caso, se conozca el margen de error que lo condiciona. 4) Que haya sido revisado por parte de un comité o consejo, de probada jerarquía científica. 5) Que se haya publicado en revistas especializadas que aplican el sistema de control preventivo por parte de científicos especializados en la rama del saber de qué se trate a fin de que certifiquen su valor científico (referato). 6) Que exista una relación directa con el caso.

23 Cfr. Fallo "Saguir y Dib, Claudia Graciela". Fallos: 302:1284 (1980).

24 Cfr. Fallo "Cisilotto, María del Carmen Baricalla de c/ Estado Nacional (Ministerio de Salud y Acción Social)". Fallos: 310:112 (1987).

25 Cfr. Fallo "Liporace, Roque c/ Vázquez Ferro, Guillermo y otros". Fallos: 312:2527 (1989).

26 Cfr. Recurso de hecho deducido por la actora en la causa "Peña de Marqués de Iraola, Jacoba María c/ Asociación Civil Hospital Alemán”. Fallos: 325:677 (2002).

27 Cfr. Fallo "Albornoz, Luis Roberto y otro c/ Provincia de Buenos Aires y otro s/ daños y perjuicios". Fallos: 331:636 (2008).

28 Cfr. Fallo "Duich Dusan, Federico c/ CEMIC (Centro de Educación Médica e Investigaciones Clínicas 'Norberto Quirno') s/ amparo”. Fallos: 337:471 (2014).

29 Cfr. Recurso de hecho deducido por la actora en la causa "Peralta, Pedro c/ Clínica Médica Integral Las Palmas y otros". Fallos: 325:677 (2002). 
Corte adopta un criterio preventivo y precautorio ${ }^{30}$, es decir, privilegiando los tratamientos con consecuencias menos gravosas, realizando una interpretación alejada de afirmaciones dogmáticas sobre la veracidad de los datos médicos ${ }^{31}$ y dando preeminencia a la efectividad objetiva del mismo en relación al fin procurado ${ }^{32}$. Estos criterios serán de utilidad a la hora de hacer una lectura de la política sanitaria propuesta a la luz de ellos.

\section{La actuación estatal, el Poder de Policía}

Ya Aristóteles advertía la existencia de una apetencia al bien que se encuentra en todos los hombres y, por extensión, en todas las instituciones $^{33}$. Esa apetencia al bien, que se manifiesta de manera ejemplar en el Estado, es lo que se denominó desde antaño "Bien Común".

Para procurar ese fin el Estado dispone de una serie de herramientas, entre las cuales encontramos el ejercicio del Poder de Policía. La existencia de esta prerrogativa se ha reconocido constitucionalmente en diversos artículos de la Carta Magna. Así, partiendo de la hermenéutica de los artículos del texto constitucional 14 primera parte ${ }^{34}, 17^{35}, 18^{36}$,

30 Cfr. Fallo "Correa, Hugo Evaristo c/ ANSeS s/ avocación”. Fallos: 330:748 (2007).

31 Cfr. Recurso de hecho deducido por la actora en la causa "Alejandro Vicente Sassone c/ Papelera Hispano Argentina S.A.”. Fallos: 307:1900 (1985).

32 Ídem, nota 26.

33 Cfr. Aristóteles (2017). La política. Madrid. Biblioteca Nueva, 21.

34 Artículo 14 de la CN: "Todos los habitantes de la Nación gozan de los siguientes derechos conforme a las leyes que reglamenten su ejercicio [...]".

35 Artículo 17 de la CN: "La propiedad es inviolable, y ningún habitante de la Nación puede ser privado de ella, sino en virtud de sentencia fundada en ley. La expropiación por causa de utilidad pública, debe ser calificada por ley y previamente indemnizada. Sólo el Congreso impone las contribuciones que se expresan en el Artículo $4^{\circ}$. Ningún servicio personal es exigible, sino en virtud de ley o de sentencia fundada en ley. Todo autor o inventor es propietario exclusivo de su obra, invento o descubrimiento, por el término que le acuerde la ley. La confiscación de bienes queda borrada para siempre del Código Penal argentino. Ningún cuerpo armado puede hacer requisiciones, ni exigir auxilios de ninguna especie".

36 Artículo 18 de la CN: "Ningún habitante de la Nación puede ser penado sin juicio previo fundado en ley anterior al hecho del proceso, ni juzgado por comisiones especiales, o sacado de los jueces designados por la ley antes del hecho de la causa. Nadie puede ser obligado a declarar contra sí mismo; ni arrestado sino en virtud de orden escrita de autoridad competente. Es inviolable la defensa en juicio de la persona y de los derechos. El domicilio es inviolable, como también la correspondencia epistolar y los papeles privados; y una ley determinará en qué casos y con qué justificativos podrá procederse a su allanamiento y ocupación. Quedan abolidos para siempre la pena de muerte por causas políticas, toda especie de tormento y los azotes. Las cárceles de la Nación serán sanas y limpias, para seguridad y no para castigo de los reos detenidos en ellas, y toda medida que a pretexto de precaución conduzca a mortificarlos más allá de lo que aquélla exija, hará responsable al juez que la autorice”. 
$19^{37}, 28^{38}$ y del inciso 18 del artículo 75 , podemos afirmar que existe un amplio elenco de derechos cuyo contenido es reconocido con carácter relativo ${ }^{39}$ y es el Estado quien posee dentro de sus facultades el deber de regular, coordinar el ejercicio de los mismos, haciéndolos compatibles con la actuación de los demás, siempre respetando la forma que la misma Constitución le impone. La doctrina nacional ha entendido que el fundamento de esta limitación se encuentra en la "comprobación social de que la convivencia o el bienestar social pueden requerir la limitación relativa de los derechos de unos para salvaguardar el derecho de otros y permitir la armonía de todos"40.

Ahora bien, al igual que el resto de los institutos del Derecho Público, el Poder de Policía reconoce limitaciones en su ejercicio. Una primera limitación se encuentra dada por la legalidad ${ }^{41}$. Esta "se traduce en la exigencia de que la actuación de la Administración se realice de conformidad al ordenamiento positivo, el cual limita o condiciona su poder jurídico" 42 . Por tanto, toda afectación o limitación sustancial a los derechos de propiedad y de libertad de los administrados debe ser indicada por vía de ley formal y los reglamentos o actos administrativos que limiten los derechos individuales, deben fundarse en precedentes legales o supralegales ${ }^{43}$. Vale aquí recordar que mediante la Opinión Consultiva 6/86 de la Corte Interamericana de Derechos Humanos la palabra "leyes", en el artículo 30 de la Convención, se refiere a una norma jurídica de carácter general, ceñida al bien común, emanada de los órganos legislativos constitucionalmente previstos y demo-

37 Artículo 19 de la $\mathrm{CN}$ : "Las acciones privadas de los hombres que de ningún modo ofendan al orden y a la moral pública, ni perjudiquen a un tercero, están sólo reservadas a Dios, y exentas de la autoridad de los magistrados. Ningún habitante de la Nación será obligado a hacer lo que no manda la ley, ni privado de lo que ella no prohíbe".

38 Artículo 28 de la CN: "Los principios, garantías y derechos reconocidos en los anteriores artículos, no podrán ser alterados por las leyes que reglamenten su ejercicio".

39 En este punto queremos destacar que, si bien hay un sector de la doctrina que sostiene que no hay derechos absolutos, otro sector, al cual nosotros adherimos, plantea que hay ciertos Derechos Humanos absolutos, los que se corresponden con deberes morales absolutos. A este respecto puede consultarse lo expuesto por el iusfilósofo John Finnis en sus obras. Finnis, J. (1980). Natural Law and Natural Rights. Oxford. Clarendon Press y Finnis, J. (1998). Aquinas: Moral, Political, and Legal Theory (Founders of Modern Political and Social Thought). Oxford. Oxford University Press, entre otros.

40 Rosatti, H. (2010). Tratado de Derecho Constitucional. T. I. Santa Fe. Rubinzal - Culzoni, 192.

41 La brevedad de este trabajo nos impide adentrarnos pormenorizadamente en el análisis de legalidad de la actuación administrativa (Decretos, Resoluciones, Disposiciones, Actos Administrativos, etc.) en el marco de la emergencia sanitaria.

42 Cassagne, J. C. (2002). Derecho Administrativo. T. II. Buenos Aires. LexisNexis - Abeledo Perrot, 26.

43 Cfr. Ibíd., 27-28. 
cráticamente elegidos, y elaborada según el procedimiento establecido por las constituciones de los Estados Partes para la formación de las leyes ${ }^{44}$.

Por otra parte, toda reglamentación no debe desnaturalizar el Derecho, debe respetar la zona de reserva que establece el artículo 19 de nuestra Carta Fundamental y mostrarse razonable. En este último punto queremos detenernos: la razonabilidad de la norma.

Linares Quintana sostiene que, para ser constitucional, toda actividad estatal debe ser razonable. Esto se traduce en que "lo razonable es lo opuesto a lo arbitrario, y significa: conforme a la razón, justo, moderado, prudente, todo lo cual puede ser resumido: con arreglo a lo que dice el sentido común" 45 .

Por otro lado, según Bidart Campos, el principio de razonabilidad de la norma, tal como fue desarrollado en el Derecho Constitucional nacional como en el estadounidense, puede identificarse con el principio de contenido esencial del Derecho que reza la Constitución de Bonn ${ }^{46}$ y la española ${ }^{47}$. De esta manera, toda la producción normativa (ora legal, ora reglamentaria), incluso en los casos que imponga limitaciones, debe respetar el contenido esencial del Derecho regulado 48 .

Otro sector de la doctrina reconoce que toda reglamentación de derechos persigue fines $y$, a esos efectos, utiliza medios que deben ser proporcionales a aquellos. Por tanto, es necesario que dicha reglamentación se presente provista de una adecuada relación entre fines y medios, y una sana equivalencia entre finalidades y mecanismos propuestos ${ }^{49}$.

En este mismo sentido, Juan Francisco Linares ha mencionado que "la garantía del debido proceso sustantivo con respecto a la ley formal y formal-

44 Ávalos, E., et al. (2014). Derecho Administrativo 1. Alveroni Ediciones, 378.

45 Linares Quintana, S. (1998). Tratado de Interpretación Constitucional. Buenos Aires. Abeledo Perrot, 559.

46 Artículo 19.1 de la Constitución de Bonn: "Cuando de acuerdo con la presente Ley Fundamental un derecho fundamental pueda ser restringido por ley o en virtud de una ley, esta debe tener carácter general y no estar limitada al caso individual. Además, la ley debe mencionar el derecho fundamental indicando el artículo correspondiente". Artículo 19.2 de la Constitución de Bonn: "Restricción de los derechos fundamentales. En ningún caso un derecho fundamental podrá ser afectado en su contenido esencial".

47 Artículo 53.1 de la Constitución española: "De las garantías de las libertades y derechos fundamentales. Los derechos y libertades reconocidos en el Capítulo segundo del presente Título vinculan a todos los poderes públicos. Sólo por ley, que en todo caso deberá respetar su contenido esencial, podrá regularse el ejercicio de tales derechos y libertades, que se tutelarán de acuerdo con lo previsto en el artículo 161, 1, a”.

48 Cfr. Bidart Campos, G. (1989). Teoría General de los Derechos Humanos. México. Universidad Nacional Autónoma de México, 240...

49 Cfr. Padilla, M. (1996). Lecciones sobre Derechos Humanos y Garantías. Buenos Aires. Abeledo Perrot. 
material es la que consiste en la exigencia constitucional de que las leyes deben ser razonables, es decir, que deben contener una equivalencia entre el hecho antecedente de la norma jurídica creada y el hecho consecuente de la prestación o sanción, teniendo en cuenta las circunstancias sociales que motivaron el acto, los fines perseguidos con él y el medio que, como prestación o sanción, establece dicho acto [...]"50.

En este punto, en concordancia con Coviello, creemos que el principio de razonabilidad tiene como elemento integrante el principio de proporcionalidad, mas no deben identificarse indistintamente, como en ocasiones los autores los han tratado ${ }^{51}$.

Por último, nos gustaría destacar que hay un sector de la doctrina que distingue un primer juicio de adecuación entre las circunstancias del caso o hechos antecedentes de la medida y los medios propuestos (razonabilidad interna de la norma), mientras reserva un segundo juicio de adecuación entre la norma en cuestión y el plexo de valores que integran la Constitución (razonabilidad externa de la norma $)^{52}$. En este mismo sentido, Solá ha planteado que "uno de los principios que orienta al Estado contemporáneo es el de que los actos estatales no deben solo emanar de una autoridad política elegida por el pueblo y ser resultado de procedimientos preestablecidos: los actos practicados en nombre de un Estado democrático de Derecho, también, además de ser legítimos [...], deben reflejar los valores e intereses de la población" ${ }^{3}$.

En nuestra materia, ¿qué define la razonabilidad en el ejercicio del Poder de Policía en un contexto científico incierto?

En función de lo mencionado anteriormente, nuestro planteo sobre la razonabilidad de la norma deberá satisfacer las exigencias que mande el sentido común, no afecte el contenido esencial del Derecho regulado, sea proporcional entre los fines buscados y la medida y se integre con el conjunto de valores que componen el plexo normativo constitucional y que forman parte del patrimonio de la población. A este respecto, valoramos el desglose que Fernando Toller propone en el análisis de razonabilidad de toda norma, abordando su 1) finalidad, 2) legitimidad, 3) adecuación, 4) necesidad, 5) proporcionalidad y 6) afectación del contenido esencial del Derecho regula-

50 Linares, J. F. (1970). Razonabilidad de las leyes: el "debido proceso" como garantía innominada en la Constitución argentina. $2^{\mathrm{a}}$ ed. Buenos Aires. Astrea, 165-166.

51 Cfr. Coviello, P. (2011). El Principio de Razonabilidad (¿̇o proporcionalidad?) en el Derecho Público Argentino. Buenos Aires. Abeledo Perrot, 144.

52 Cfr. Quiroga Lavié, H., et al (2009). Derecho Constitucional Argentino. T. I. $2^{\mathrm{a}}$ ed. Santa Fe. Rubinzal - Culzoni.

53 Solá, J. V. (2006). Control Judicial de Constitucionalidad. $2^{\mathrm{a}}$ ed. Buenos Aires. Lexis Nexis, 579. 
$\mathrm{do}^{54}$. Desarrollaremos muy brevemente los puntos 1 y 2 , los cuales daremos por satisfechos, a fin de adentrarnos pormenorizadamente en los puntos 3 $\mathrm{y}$ siguientes.

\section{III.a. Finalidad}

En términos generales, toda norma de policía se procura una finalidad. Más específicamente, en materia sanitaria, las normas de policía buscan la preservación de la salud como su recomposición cuando ella ha sido disminuida.

En nuestro caso, la finalidad de la norma (cualquiera sea su manifestación) estará dada principalmente por la disminución tendiente a cero de la población infectada por el virus SARS-CoV. A su vez, también podría plantearse como hipótesis de trabajo que el ejercicio del Poder de Policía busca brindar seguridades a la población en lo que se refiere a la implementación de tratamientos científico-médicos en etapas de investigación por su reciente difusión.

Este sentido teleológico que poseería cualquier norma que pudiera dictarse en este aspecto, da por satisfecho a nuestros efectos, incluso en abstracto, el primero de los recaudos de razonabilidad de la norma. No se nos escapa en esta consideración que el Estado podría incurrir en prácticas irrazonables a través del dictado de normas carentes de finalidad o con finalidades oscuras ajenas al interés superior del paciente.

\section{III.b. Legitimidad}

El Estado, es sabido, tiene vedado obrar por fines espurios o inhabilitados por la ley y actuar de ese modo resultaría no solo irrazonable sino escandaloso. Ahora bien, en nuestro estudio (el cual desarrollamos en abstracto a los fines académicos), partiendo del principio de buena fe que debe dirigir toda la actividad jurídica, la presunción de legitimidad de los actos de gobierno y la presunción de constitucionalidad de las normas, daremos por satisfecho este punto en el test sobre la razonabilidad de la norma sin dejar antes de mencionar algunos recaudos que deben tenerse en cuenta.

Desde hace algunos años, un sector de la doctrina nacional ha venido desarrollando, a partir de jurisprudencia del Máximo Tribunal, el concep-

54 Toller, F. (2014), “Interpretación de los Derechos Constitucionales”. En Rivera, J. C. (h). Tratado de los Derechos Constitucionales. Obra colectiva. T. I. Abeledo Perrot, 166 y sigs. 
to de "normas portadoras de una presunción de inconstitucionalidad" y ha abordado el impacto de ellas en el Derecho Público, en cuanto a la causa y objeto de los actos administrativos, integración del bloque de juridicidad, afectación del principio de legitimidad de los actos administrativos y las exigencias de actuación de la Administración ${ }^{55}$. Esta inclinación de la doctrina impacta necesariamente sobre la presunción de legitimidad de los actos administrativos y, nos atrevemos a incoar, en la presunción de constitucionalidad de las normas.

En este sentido, la Corte ha tenido oportunidad de expedirse en "Gottschau, Evelyn Patrizia c/ Consejo de la Magistratura de la Ciudad Autónoma de Buenos Aires s/ amparo", sentencia del 8 de agosto de 2006, donde sostuvo que "cuando se impugna una categoría infraconstitucional basada en el 'origen nacional', como sucede en el sub lite, corresponde considerarla sospechosa de discriminación y portadora de una presunción de inconstitucionalidad que corresponde a la demandada levantar"56.

No puede desconocerse que, en materia de reglamentación sanitaria, el ejercicio del Poder de Policía podría desplegarse en el dictado de normas con requisitos particularísimos que tiendan a desalentar la competencia y concurrencia de variantes terapéuticas, basados en criterios de oportunidad y conveniencia, alejados de basamentos científicos.

En estos casos, al igual que sucede con la categoría de "nacional" para el acceso a determinados cargos públicos, este racaudo de la norma podría ser cuestionado con independencia de encontrarse bajo la apariencia de legitimidad. No obstante, a nuestros efectos, también daremos por satisfecho este recaudo. Creemos que la clave de bóveda acerca de la razonabilidad de la norma estará dada por el siguiente principio.

\section{III.c. Adecuación}

A nuestro entender, resulta sencillo el estudio de este recaudo cuando la ineptitud o efectividad del medio en relación al fin es evidente y fruto de la probada experiencia. Ahora bien, los casos de complejidad relativa o alta (como aquellos donde no hay certeza de los posibles efectos clínicos paradojales) requieren una atención y dedicación especial. Así, los tratamientos

55 Cfr. Sammartino, P. (2009). "La causa y el objeto del acto administrativo en el Estado constitucional”. En AA. VV. Cuestiones de Acto Administrativo, Reglamento y otras Fuentes del Derecho Administrativo. Jornadas organizadas por la Universidad Austral. Facultad de Derecho. Buenos Aires. Ediciones Rap, 59-77.

56 En este mismo sentido, podemos destacar la causa "Hooft", Fallos: 327:5118, considerando $4^{\circ}$. 
médicos en general, y la atención del SARS-CoV en particular, se encuadran dentro de este último conjunto.

Como se ha mencionado anteriormente a la luz de la jurisprudencia de la CSJN, la complejidad de la materia médica es innegable y una manifestación de esa complejidad es la actual diversidad de opiniones científicas que se suscitan al respecto del SARS-CoV.

En esta línea, comenta Mariano Sapag que "[l]a adecuación se debe analizar en el momento y las circunstancias de la aplicación de la norma" ${ }^{57}$. En parte y aplicado a nuestra materia, esto se debe a que existe una verdadera diversificación de técnicas y procedimientos que permiten abordar las demandas de salud de distintas maneras y con distintos grados de efectividad.

Además (especialmente en las circunstancias que nos tocan atravesar frente al avance de la pandemia), el progreso del conocimiento científico y su aceleración de continuo proponen y seguirán proponiendo nuevos modelos de tratamiento que hasta entonces habían sido desconocidos. De tal manera que la adecuación de los tratamientos y la finalidad buscada no pueden ser analizadas en abstracto y haciendo cosa juzgada, sino que deben encontrarse permanentemente abiertas y expuestas al confronte del profesional que las propone como medios idóneos ${ }^{58}$.

Agregamos aquí que la adecuación entre la medida y la finalidad que pretende satisfacer dependerá, en gran medida, de la casuística individual de cada paciente. Más aún, puede darse el caso de que la misma medida clínica resulte insuficiente o incluso ineficaz para algunos, y altamente confiable en sus resultados para otros casos de similares características.

En este punto, entendemos que habría que estarse al aporte concreto del profesional que participa de la relación médico-paciente, el cual, por las características propias de la relación conmutativa, conoce con mayor claridad el estado clínico de aquél y las implicancias de asumir determinados tratamientos.

Por otro lado, en lo que se refiere a la postura que debería asumir la Administración, como se mencionó supra, el principio rector en materia de clínica médica es equipoise, por tanto, frente a la ausencia de pruebas con-

57 Sapag, M. (2008). "El principio de proporcionalidad y de razonabilidad como límite constitucional al poder del Estado: un estudio comparado". Dikaion, Año 22, Nro. 17, 157-198.

58 En este sentido, dice Blas Orbán, C.: "[e]l hecho de que la llamada ciencia médica no pueda aspirar ya al estatuto de cierta o verdadera, sino sólo de verificable, hace que sus conclusiones tengan que estar en continua revisión. Esto hace que muchas veces haya un cierto desfase entre la ciencia médica (lo que podríamos llamar la 'Ley médica') y la Ley jurídica. Por ello, la medicina está continuamente definiendo lo que es científicamente correcto". Blas Orbán, C. (2006). El equilibrio en la relación médico-paciente. Madrid. J. M. Bosch, 36. 
tundentes sobre la capacidad curativa y ausencia de efectos no deseados, los médicos no deben recomendar dichos tratamientos.

Este principio rector en materia clínica ya había sido recogido por la Ley de Medicamentos $\mathrm{N}^{\circ} 16.463$, utilizando como criterio de validación la acción farmacológica y utilidad terapéutica reconocidas de aquellos ${ }^{59}$.

Dicho esto, nos podemos preguntar: ¿qué características debería revestir la norma de policía para ser considerada adecuada? Teniendo presente lo antes mencionado, la norma de policía, en primer lugar, debería reconocer ese principio de incertidumbre científica evitando la exigencia de tratamientos cuyas ventajas terapéuticas sean desconocidas o se encuentren en fase de exploración.

En segundo lugar, teniendo en cuenta la jurisprudencia de la Corte, la norma debería basar su juicio de adecuación en la efectividad objetiva del tratamiento propuesto a la luz de la evidencia científica disponible ${ }^{60}$.

En tercer lugar, incluso contando con evidencia científica disponible acerca de los efectos positivos y paradojales del tratamiento, la norma debería respetar un margen de apreciación médica ${ }^{61}$ donde el galeno pondere el contenido de la misma y la subsuma en el caso particular, velando que su contenido se traduzca en una respuesta tendiente a resolver (o al menos mejorar) la patología del paciente.

\section{III.d. Necesidad}

Naturalmente, al igual que en la conducta humana entendida como razonable, en el caso de multiplicidad de opciones válidas, el Estado está llamado a optar por la menos gravosa. Este razonamiento no es más que una de las manifestaciones lógicas del principio favor libertatis. En el caso del ejercicio del Poder de Policía, habrá que estarse a las distintas opciones válidamente aceptables, que prescribieren procedimientos, técnicas o tratamientos menos gravosos para los pacientes. En términos similares, Mariano Sapag dirá: "[e]s una exigencia del principio de razonabilidad que la norma que se adopte para alcanzar la finalidad requerida sea la mejor, y no sólo la eficaz (adecuada). Para esto es necesario considerar las circunstancias de la medida: tiempo, modo y lugar; en este sentido, la norma razonable será,

59 Cfr. Artículo 10, Ley No 16.463: "El Ministerio de Asistencia Social y Salud Pública redactará, publicará y revisará periódicamente el Formulario Terapéutico Nacional, el que contendrá la recopilación de fórmulas magistrales de uso frecuente y de acción farmacológica y utilidad terapéutica reconocidas".

60 Ídem, nota 23.

61 Ídem, nota 26. 
entre otras cosas, la que resulte más económica, la que logre la finalidad en el menor tiempo posible, la que conlleve los menores costos y esfuerzos para la comunidad, la que regule la menor cantidad de supuestos de hecho y sujetos alcanzados, etc." 62 .

Reiteramos aquí lo dicho en el punto anterior. El progreso de la ciencia médica exige al profesional de la salud replantearse de continuo la eficacia y conveniencia entre el medio impuesto y la finalidad buscada. En este juego, es el profesional de la salud quien identifica in acto el tratamiento necesario según el conocimiento científico disponible en ese momento. De igual modo que en el recaudo de la adecuación, la determinación del medio más idóneo y menos gravoso dependerá de la condición del paciente, las circunstancias del caso y su aptitud para recibir determinada práctica médica.

Nuestra intención, en lo que a nuestra materia concierne, es proponer criterios de análisis para la selección de tratamientos eficientes. Así, consideramos que la norma de policía debería priorizar los tratamientos que, según la evidencia científica disponible a la luz de la efectividad objetiva del tratamiento, ponderen los siguientes elementos: menor cantidad de riesgos colaterales, mayores expectativas de mejora, menor duración de tratamiento y mayor tiempo en circulación cuya acción antiviral tenga carácter probado.

\section{III.e. Proporcionalidad}

El principio de proporcionalidad terapéutica se basa en el pronóstico clínico individual y en la situación particular de cada enfermo. En este punto, las medidas terapéuticas ordinarias (o proporcionales) son aquellas que siempre se deben aplicar pues de ellas dependen la preservación de la vida y la salud. Por el contrario, las medidas extraordinarias (o desproporcionales) son aquellas que, por diversos motivos, pueden no ser necesario realizar; y en este punto resulta de capital importancia el consentimiento informado del paciente.

A este respecto, igual que sucede en los puntos anteriores, el análisis de proporcionalidad deberá hacerse para cada caso en particular, teniendo en cuenta la multiplicidad de pacientes, las distintas manifestaciones de la misma enfermedad que pueden darse en la población y la inconmensurable cantidad de respuestas de cada organismo en particular.

De esta manera, la norma de policía sanitaria razonable será aquella que permita al galeno decidir sobre la factibilidad de dicho tratamiento a la

62 Ídem, nota 56. 
luz de las "razonables probabilidades de beneficio en términos de preservar y/o recuperar la salud"63.

En este sentido, y a fin de no caer en vaguedad, el Consejo Pontificio para la Pastoral de la Salud ha elaborado algunos criterios para el análisis de proporcionalidad terapéutica. Así, "con el propósito de verificar y establecer si se da o no la relación de proporción en una determinada situación, se deben valorar bien los medios confrontando el tipo de terapia, el grado de dificultad y el riesgo que comporta, los costos necesarios y la posibilidad de aplicación, con el resultado esperado, teniendo en cuenta las condiciones del enfermo y sus fuerzas físicas y morales" 64 .

\section{III.f. Afectación al contenido esencial del Derecho}

Junto con los derechos a la vida, a la protección de la salud y a la autodeterminación, el ordenamiento jurídico reconoce a los pacientes el derecho a la atención médica de buena calidad ${ }^{65}$. Este derecho incluye el derecho a la opinión clínica y ética, profesionalmente libre e independiente, sin interferencias exteriores; idea que se ve reforzada por el deber de independencia científica que recae en cabeza de todos los profesionales de la salud, conforme el Código Internacional de Ética Médica y cuya observancia normativa ha sido reconocida por la Corte $^{66}$.

Ahora bien, el derecho a una opinión libre e independiente hace posible a los profesionales el abordaje de los casos clínicos complejos basándose en los elementos aportados por la ciencia orientados a la efectividad objetiva del tratamiento, lo cual también constituye un derecho del paciente ${ }^{67}$. A su vez, el ejercicio de esa opinión profesional libre e independiente que procura la efectividad objetiva del tratamiento sólo puede desplegarse en un ámbito de discrecionalidad médica en donde el galeno pueda contar con libertad para ejercer su ciencia. En esta línea, la jurisprudencia ha reconocido en sus fallos la presencia de ese ámbito de discrecionalidad profesional en el

63 Taboada Rodríguez, P. (2018). "El principio de proporcionalidad terapéutica en las decisiones de limitar tratamientos". ARS MÉDICA Revista de Ciencias Médicas, 27(1).

64 Pontificio Consejo para la Pastoral de los Agentes de la Salud (1994). Carta a los Agentes de la Salud. Buenos Aires. Ed. Paulinas, 71.

65 Cfr. Declaración de Lisboa sobre los Derechos de los Pacientes, Asociación Médica Mundial, adoptada por la $34^{\text {a }}$ Asamblea Médica Mundial Lisboa, Portugal, septiembre/octubre 1981 y enmendada por la $47^{\mathrm{a}}$ Asamblea General Bali, Indonesia, septiembre 1995 y revisada su redacción en la $171^{\text {a }}$ Sesión del Consejo, Santiago, Chile, octubre 2005.

66 CSJN. "Medilewski, Jacobo Rubén c/ Szarfman, Isaac”. Fallos: 310:1536 (1987).

67 Ídem, nota 64. 
ejercicio de la Medicina ${ }^{68}$. En este mismo sentido, el Código de Ética de la Asociación Médica Argentina establece que los profesionales tienen derecho al respeto de un margen de discrecionalidad médica que asegure al galeno un espacio de libertad científica.

El ejercicio de la profesión liberal y el reconocimiento del ámbito de discrecionalidad terapéutica deben siempre entenderse en el respeto más pleno del derecho de autodeterminación del paciente. El derecho a la autodeterminación implica, a su vez, el derecho al acceso a información veraz y suficiente sobre persona y estado del paciente. Ambos se encuentran solemnemente reconocidos en la Ley $\mathrm{N}^{\circ} 26.529$, con el nombre de Autonomía de la Voluntad $^{69}$ e Información Sanitaria ${ }^{70}$.

En definitiva, el trinomio formado por el ámbito de discrecionalidad terapéutica, opinión libre e independiente y efectividad objetiva del tratamiento constituye la fortaleza que permite al profesional la asistencia al paciente fuera de posiciones dogmáticas y aplicando toda su ciencia en beneficio de aquél. Por eso, esa fortaleza no sólo garantiza el libre ejercicio profesional, sino que salvaguarda íntegramente el derecho de los pacientes a una atención médica de buena calidad. Por tanto, consideramos que cualquier normativa que desconozca alguno de estos tres elementos podría caer por irrazonable, ora por un defecto en la adecuación, necesidad y/o proporcionalidad, ora por afectar el contenido esencial de estos derechos.

\section{Conclusiones}

Resumiendo, podemos indicar que:

a. Según la jurisprudencia de la CSJN de los últimos cuarenta años, en los casos de duda sobre determinadas prestaciones o prácticas médicas, se debe partir del principio de incertidumbre clínica, asumiendo una posición preventiva y precautoria, alejada de posiciones dogmáticas y basadas en la efectividad objetiva de las mismas inter-

68 Ídem, nota 26.

69 Artículo $2^{\circ}$, inciso e) de la Ley $\mathrm{N}^{\circ}$ 26.529: "Autonomía de la Voluntad. El paciente tiene derecho a aceptar o rechazar determinadas terapias o procedimientos médicos o biológicos, con o sin expresión de causa, como así también a revocar posteriormente su manifestación de la voluntad. Los niños, niñas y adolescentes tienen derecho a intervenir en los términos de la Ley $\mathrm{N}^{\circ} 26.061$ a los fines de la toma de decisión sobre terapias o procedimientos médicos o biológicos que involucren su vida o salud".

70 Artículo $2^{\circ}$, inciso f) de la Ley $\mathrm{N}^{\circ}$ 26.529: "Información Sanitaria. El paciente tiene derecho a recibir la información sanitaria necesaria, vinculada a su salud. El derecho a la información sanitaria incluye el de no recibir la mencionada información". 
pretadas a la luz de la evidencia científica, desestimando aquellos tratamientos cuyas bondades terapéuticas no se encuentran acreditadas suficientemente.

b. La multiplicidad de criterios médicos, el avance del progreso científico, la diversidad de pacientes y las diferentes manifestaciones patológicas llevan a que la opción terapéutica adecuada, necesaria y proporcional sea determinada in acto en el marco de la relación conmutativa médico-paciente.

c. El ámbito de discrecionalidad médica, la opinión profesional libre e independiente y la efectividad objetiva del tratamiento integran el derecho de los pacientes a una atención médica de buena calidad, el cual constituye un deber en sentido estricto para los galenos.

d. Las normas de policía que desconocen el trinomio compuesto por los elementos del punto c), en su aplicación, podrían reputarse como irrazonables por presentar un vicio en la adecuación, necesidad o proporcionalidad y/o por afectar el contenido esencial de derechos.

A modo de conclusión, nos animamos a proponer una respuesta a nuestra pregunta inicial acerca de cuál sería una postura razonable a asumir por el Estado en su rol de contralor sanitario frente a un escenario de pandemia y con un panorama científico incierto. Entendemos que, frente a un panorama de pandemia, con un escenario científico incierto, guiados por el interés superior del paciente, el Estado debe asumir una posición precautoria y preventiva con relación a las múltiples prestaciones propuestas por el progreso científico, privilegiando sólo aquellas cuyos efectos deseados se encuentran acreditados y presenten las consecuencias menos gravosas. $\mathrm{Y}$ así, esta postura precautoria se debería cristalizar en normas de policía sanitarias que sean dictadas tomando como criterio la efectividad objetiva del tratamiento a la luz de la evidencia científica disponible y respetando el ámbito de discrecionalidad médica y el ejercicio de la opinión profesional libre e independiente.

\section{Bibliografía}

Aristóteles (2017). La política. Madrid. Biblioteca Nueva, 21.

Artigas, M. (1999). Filosofía de la Ciencia. Navarra. Ediciones Universidad de Navarra S.A. (EUNSA), 255.

Ávalos, E., et al. (2014). Derecho Administrativo 1. Alveroni Ediciones, 378.

Bidart Campos, G. (1989). Teoría General de los Derechos Humanos. México. Universidad Nacional Autónoma de México, 240. 
Blas Orbán, C. (2006). El equilibrio en la relación médico-paciente. Madrid. J. M. Bosch, 36.

Cao, Y., et al. (Marzo 2020). "A Trial of Lopinavir-Ritonavir in Adults Hospitalized with Severe COVID-19”. The New England Journal of Medicine, Nro. 382, 1787-1799.

Cassagne, J. C. (2002). Derecho Administrativo. T. II. Buenos Aires. LexisNexis - Abeledo Perrot, 26.

Changeux, J., et al. (Abril 2020). "A nicotinic hypothesis for COVID-19 with preventive and therapeutic implications". Qeios, https://doi.org/10.32388/FXGQSB.2.

Chen, J., et al. (Marzo 2020). "A pilot study of hydroxychloroquine in treatment of patients with common coronavirus disease-19 (COVID-19)". Journal of Zhejiang University, Nro. 46, 215-219.

Coviello, P. (2011). El Principio de Razonabilidad (¿o proporcionalidad?) en el Derecho Público Argentino. Buenos Aires. Abeledo Perrot, 144.

De Broglie, L. (1955). Physiscs and Microphysics. Traducción de Davidson, M. Nueva York. Panteon Books, 84.

Finnis, J. (1980). Natural Law and Natural Rights. Oxford. Clarendon Press y Finnis, J. (1998). Aquinas: Moral, Political, and Legal Theory (Founders of Modern Political and Social Thought). Oxford. Oxford University Press, entre otros.

Freedman, B. (Julio 1987). "Equipoise and the Ethics of Clinical Research". The New England Journal of Medicine, Nro. 317, 141-145.

Hubner, K. (1981). Crítica de la razón científica. Barcelona. Alfa, 115.

Kramer, D., et al. (7 de abril 2020). "Equipoise on COVID-19 therapeutics". The BMJ Opinion, https://www.blogs.bmj.com/bmj/2020/04/07/equipoise-on-life-support.

Linares, J. F. (1970). Razonabilidad de las leyes: el "debido proceso" como garantía innominada en la Constitución argentina. $2^{\text {a }}$ ed. Buenos Aires. Astrea, 165-166.

Linares Quintana, S. (1998). Tratado de Interpretación Constitucional. Buenos Aires. Abeledo Perrot, 559.

Padilla, M. (1996). Lecciones sobre Derechos Humanos y Garantías. Buenos Aires. Abeledo Perrot.

Pontificio Consejo para la Pastoral de los Agentes de la Salud (1994). Carta a los Agentes de la Salud. Buenos Aires. Ed. Paulinas, 71.

Quiroga Lavié, H., et al (2009). Derecho Constitucional Argentino. T. I. $2^{\mathrm{a}}$ ed. Santa Fe. Rubinzal- Culzoni.

Rosatti, H. (2010). Tratado de Derecho Constitucional. T. I. Santa Fe. Rubinzal - Culzoni, 192.

Sammartino, P. (2009). "La causa y el objeto del acto administrativo en el Estado constitucional". En AA. VV. Cuestiones de Acto Administrativo, Reglamento y otras Fuentes del Derecho Administrativo. Jornadas organizadas por la Universidad Austral. Facultad de Derecho. Buenos Aires. Ediciones Rap, 59-77.

Sapag, M. (2008). "El principio de proporcionalidad y de razonabilidad como límite constitucional al poder del Estado: un estudio comparado". Dikaion, Año 22, Nro. 17, 157-198.

Solá, J. V. (2006). Control Judicial de Constitucionalidad. $2^{\mathrm{a}}$ ed. Buenos Aires. Lexis Nexis, 579. 
Soler Pérez, E. (2015). Derecho Administrativo: Lecciones de la Universidad de Valencia 1906-1907. Sevilla. Athenaica Ediciones Universitarias, 295.

Taboada Rodríguez, P. (2018). "El principio de proporcionalidad terapéutica en las decisiones de limitar tratamientos”. ARS MÉDICA Revista de Ciencias Médicas, 27(1).

Toller, F. (2014), "Interpretación de los Derechos Constitucionales". En Rivera, J. C. (h). Tratado de los Derechos Constitucionales. Obra colectiva. T. I. Abeledo Perrot, 166 y sigs.

University Of Camberra (2019). "Evidence-Based Practice in Health", 16-6-2020, University Of Caberra Library. Recuperado de: canberra.libguides.com/c. $\mathrm{php}$ ? $=599346 \& \mathrm{p}=4149721$.

Ziman, J. (1981). La credibilidad de la ciencia. Madrid. Alianza, 224. 